\title{
LIÇÕES DE UM XAMÃ YANOMAMI PARA A CONSTRUÇÃO DE UMA IDENTIDADE PÓS- ANTROPOCÊNTRICA
}

\author{
Lessons from a Yanomami shaman for the construction of a post-anthropocentric identity \\ Lecciones de un chaman Yanomami para la construcción de una identidad post-antropocéntrica
}

Douglas KaWAGuChi ${ }^{1}$

\begin{abstract}
Resumo: O imaginário da cultura ocidental reserva à figura do humano um lugar excepcional e identificado com a totalidade cosmológica: a "humanidade" é dada como certa na construção da identidade, ao mesmo tempo em que se atribui aos seres não-humanos um estatuto de não-sujeitos. Este trabalho parte do pressuposto de que esta visão de mundo se ancora sobre uma estrutura fundamentalmente mítica, que tem como um importante representante a narrativa de criação do mundo da Bíblia Hebraico-Cristã. Sendo assim, este trabalho propõe uma análise das relações entre humanidade e animalidade expressas no Gênesis, primeiro livro da Bíblia, comparando-as com a forma como essas mesmas relações são expressas em um mito de criação ameríndio: A Queda do Céu: palavras de um xamã Yanomami, de autoria do xamã e líder indígena Davi Kopenawa. Os resultados são interpretados a partir de um diálogo entre antropologia do imaginário e psicologia cultural e sinalizam que, diferentemente do que ocorre na narrativa adotada pela cultura ocidental, na ameríndia a animalidade e humanidade figuram como partes de um mesmo todo, imanentemente presentes em todos os seres, de tal modo que o contato com ancestrais espirituais somente é considerado possível com a mediação animal - o que faz da "natureza" uma dimensão fundamental do "divino" na cosmologia Yanomami. Discutese as implicações destes achados com relação a um pressuposto fundamental do pensamento psicológico: a noção de humanidade.
\end{abstract}

Palavras-chave: Imaginário; Psicologia Cultural; Mitos; Antropocentrismo; Identidade

\begin{abstract}
Western culture's imaginary positions human figure as exceptional and identified with cosmological wholeness: "humanity" is taken for granted in the construction of people's identity, while non-human beings are assigned a condition of non-subjects. This paper departs from the assumption that this worldview is supported by a fundamentally mythical structure, which has, as an important representant, world creation narrative expressed in the Hebrew-Christian Bible. Thus, this paper proposes an analysis of the relations between humanity and animality that are expressed in The Book of Genesis, first book of the Bible, comparing them with the way those same relations are expressed in an Amerindian creation myth: The Falling Sky: Words from a Yanomami shaman, from indigenous leader and shaman David Kopenawa. The results are interpreted from a dialogue between anthropology of the imaginary and cultural psychology and show that, unlike Western narrative, in Amerindian animality and humanity figure like parts of the same whole, immanently present in all beings: the contact with spiritual ancestors is only possible through animal mediation, which makes "nature" a fundamental dimension of the "divine" in Yanomami cosmology. I discuss the implications of these findings for a fundamental assumption of psychological thought: the notion of humanity
\end{abstract}

Keywords: Imaginary; Cultural Psychology; Myths; Anthropocentrism; Identity

Resumen: El imaginario de la cultura occidental reserva a la figura humana un lugar excepcional y identificado con la totalidad cosmológica: la "humanidad" se dá por certo en la construcción de la identidad de las personas, mientras que los seres no humanos están relegados a una condición de no sujetos. Este artículo parte del supuesto de que esta cosmovisión anclas en una estructura fundamentalmente mítica, que tiene como importante representante la narrativa de la creación del mundo presente en la Biblia Hebreo-Cristiana. Por ello, este trabajo propone un análisis de las relaciones entre humanidad y animalidad expresadas en Génesis, el primer libro de la Biblia, comparándolas con la forma en que estas mismas relaciones se expresan en un mito de la creación amerindio: La Caída del Cielo: palabras de un chamán Yanomami, de autoría del líder indígena y chamán David Kopenawa. Los resultados son interpretados desde un dialogo entre la antropología del imaginário y la psicología cultural y señalan que, a diferencia de la narrativa occidental, en la amerindia la "animalidade" y la "humanidade" figuran como partes del mismo todo, inmanentemente presentes en todos los seres, tal que el contacto con los antepasados espirituales solo se considera posible a través de la mediación animal, lo que hace de la "naturaliza" una dimensión fundamental de lo "divino" en la cosmología Yanomami. Las implicaciones de estos hallazgos se discuten en relación con un supuesto fundamental del pensamiento psicológico: la noción de humanidad.

Palavras-clave: Imaginario; Psicología Cultural; Mitos; Antropocentrismo; Identidad. 


\section{Introdução}

\author{
“E disse Deus: façamos o Homem à nossa \\ imagem, \\ conforme a nossa semelhança; e domine sobre \\ os peixes do mar, \\ e sobre as aves dos céus, e sobre o gado, e \\ sobre toda a terra, \\ e sobre todo réptil que se move sobre a terra”
}

(Gênesis, 1:26)

A noção do Humano ${ }^{1}$ como centro e totalidade cosmológica, único sujeito num mundo de seresobjetos destinados a seu uso, está presente na cultura ocidental há milênios, sendo crescentemente reafirmada nos séculos recentes por uma realidade cultural de exploração massiva de animais nãohumanos e "recursos" naturais. Esta visão de mundo não apenas traz graves implicações éticas ${ }^{2}$, ambientais $^{3}$ e de saúde pública ${ }^{4}$, como também é frequentemente assumida, de forma inadvertida, como pressuposto epistemológico na psicologia e em outras áreas do conhecimento. Este trabalho argumenta que não apenas esta é uma cosmovisão arbitrária, mas a própria ideia de humanidade, como identidade coesa e compartilhada por toda a espécie humana (e seu oposto, a animalidade), é antes de tudo um fenômeno específico da cultura ocidental. Para nos aprofundarmos nessa questão, servimonos de um diálogo entre a psicologia cultural (Boesch, 1991; Guimarães, 2016; Valsiner, 2012) e a antropologia do imaginário (Durand, 2012), de modo a analisar um trecho da Bíblia Hebraico-Cristã que corresponde à criação do mundo, comparando-o com a narrativa de criação do mundo de uma cultura absolutamente diversa, a Yanomami (Kopenawa \& Albert, 2015).

A Bíblia é o livro mais vendido da história ${ }^{5}$ : sua influência na cultura ocidental é incontestável e está presente não apenas nos discursos religioso e teológico, mas no filosófico, artístico, político e científico (cf. Gadamer, 1954/2010; Kawaguchi \& Guimarães, 2019). A partir do conceito de "narrativa-mestra” proposto por Hammack (2010), podemos compreender a narrativa bíblica como um estruturante fundamental do pensamento ocidental

\footnotetext{
1 A grafia da palavra "humano" aparece de três diferentes formas neste trabalho, de modo a diferenciar a cultura na qual está referenciada e sua função sintática. Essas definições são detalhadas no parágrafo final da Introdução.

2 Como a legitimação do tratamento abusivo dispensado pela indústria a dezenas de bilhões de animais não-humanos todos os anos (Kawaguchi, 2017).

3 A catástrofe ambiental que vivemos atualmente (Danowski \& Viveiros de Castro, 2014).

4 Nas patologias relacionadas a nossa desconexão com a "natureza" dentro e fora de nós.

5 Foram 3,9 bilhões de exemplares só nos últimos cinquenta anos, o equivalente a mais de duas vezes a soma dos outros nove livros mais vendidos (Chapman, 2015). Segundo o Guinness World Records [GWR] (2016), são mais de 5 bilhões de cópias ao longo de toda a história.
}

atual, de modo que estudar um aspecto do Gênesis é analisar um estruturador mítico da visão de mundo da cultura ocidental. A compreensão de “mito” e "narrativa mítica” aqui utilizada é aquela proposta pela psicologia cultural (Boesch, 1991; Valsiner, 2012), em que mito não se opõe a verdade, tampouco está restrito ao campo religioso: mito é o fundamento último de toda construção de sentido e, assim sendo, é arbitrário, não podendo ser racionalmente questionado. Segundo esta concepção, qualquer compreensão de significado repousa, em última instância, sobre uma imagem ou narrativa dada culturalmente através de uma tradição: o mito. Como se pode notar, esta vertente da psicologia privilegia a diferença, a especificidade cultural do estudo do mito, sendo este um dos motivos pelos quais a interdisciplinaridade é entendida como necessária para uma boa compreensão do outro em sua singularidade - e, no caso do encontro interétnico, como o aqui proposto, a antropologia é convocada como um auxílio para nos deslocarmos de nossa perspectiva inicial, em direção à do outro, para chegarmos a uma terceira posição em que a compreensão seja possível (cf. Simão, 2010; Viveiros de Castro, 2004).

Mas nem só de diferença se faz a compreensão do outro. Na análise comparada entre mitos aqui apresentada, chama a atenção uma oposição complementar fundamental, que parece apontar para uma semelhança anterior, que está por trás de toda diferença. Por isso, convocou-se ao estudo a noção de arquetipologia de Gilbert Durand (2012), cuja proposição de "regimes diurno e noturno" do imaginário parece ser contributiva. Isso trouxe complexidade ao trabalho, por conta de conjugar um olhar para a semelhança por trás da diferença, ao mesmo tempo em que para a especificidade que surge do elementar. De fato, o resultado foi o surgimento de uma noção de "humano" surpreendentemente nova, nem ocidental, nem Yanomami. Mas por que a comparação especificamente com uma cultura ameríndia? Os dois próximos parágrafos buscam esclarecer isto.

Descola (1996, 2005) avaliou estudos antropológicos de povos do mundo inteiro e chegou à conclusão de que a ontologia ocidental é a única a operar esta cisão radical que separa Humano e natureza, pressupondo a "interioridade" (alma, consciência, pensamento, intenção, cultura, etc.) como unicamente humana e "exterioridade" ("corpo") como assemelhada entre todas as espécies: visão chamada de naturalismo; as demais culturas possuiriam ontologias majoritariamente diversas, chamadas animismo, totemismo e analogismo. Concentremo-nos na ontologia preponderante nos povos ameríndios: o animismo, inverso do naturalismo, que pressupõe semelhança de interioridade entre todos os seres (todos possuiriam o que chamamos de "alma", sejam "humanos", 
animais não-humanos, plantas, etc.) e diferença de exterioridade (embora todos seres possuam um "espírito" aparentado, cada um se apresenta numa "corporeidade" distinta, inclusive "humanos" de outra etnia). Viveiros de Castro (1996, 2006) defende uma visão dessa cosmologia chamada de "perspectivismo ameríndio", segundo a qual os povos ameríndios pressupõem que todos seres enxergam a si mesmos como "humanos", de modo que um "humano" vê uma onça como uma onça e um queixada (um mamífero assemelhado ao javali) como um queixada, mas a onça vê o "humano" como queixada e o queixada vê o "humano" como onça (ou seja, a perspectiva de predação seria transposta), além de que um "humano" de outra etnia também é visto como "não-humano". Ou seja, a "cultura" (o modo de ver, ou perspectiva) seria compartilhada entre todos os seres, mas a "natureza" não: cada corpo se apresenta de um modo distinto. Trata-se, portanto, de uma cosmologia antes etnocêntrica do que antropocêntrica.

Esta visão, que não apenas inverte as noções de dentro e fora, humanidade e animalidade, mas coloca em perspectiva a própria noção de humanidade como absoluta, pareceu uma forma potente de se olhar com distanciamento crítico para o imaginário ocidental sobre a relação entre humanidade e animalidade, de modo a desconstruí-lo e, no contraste entre diferentes, encontrar talvez uma terceira e nova possibilidade. Por isso, realizei uma análise comparativa entre o mais difundido mito de criação da cultura ocidental e o mito de criação de uma cultura ameríndia que tem chamado a atenção das ciências humanas no mundo inteiro: o Gênesis, primeiro livro ${ }^{6}$ da Bíblia Hebraico-Cristã e A Queda do Céu: Palavras de um xamã Yanomami (Kopenawa \& Albert, 2015) ${ }^{7}$, que reúne as narrativas do xamã Davi Kopenawa registradas pelo antropólogo Bruce Albert ao longo de mais de uma década, retratando a cosmologia dos Yanomami, um dos maiores povos amazônicos que ainda conservam seu modo de vida tradicional - obra considerada um acontecimento antropológico comparável apenas ao revolucionário Tristes Trópicos (Viveiros de Castro, 2015, pp. 1112). Os próximos dois parágrafos trazem um resumo dessa análise, publicada integralmente em ocasião anterior (Kawaguchi \& Guimarães, 2019).

No Gênesis, o criador do mundo é um Deus que parece Humano, se comporta como Humano e dedica toda sua criação ao Humano. Os animais, plantas e tudo o mais são criados explicitamente para o domínio e uso do Humano. Desde o início, Deus opera separações estritas: dia/noite, luz/trevas, céu/terra, Humanos/animais, etc. A origem divina humana é lugar da pureza, liberdade e ausência de dor; seu presente, lugar dos animais e de sofrimento, dor, trabalho duro, pecado e maldição, é para onde os Humanos (Adão e Eva) são expulsos, como

6 Os três primeiros capítulos.

7 Capítulos dois e quatro. punição por se envolverem com a animalidade (a Serpente). As relações ontológicas são unilaterais: Deus define Adão, Adão define Eva, Deus define o mundo (pela criação) e Adão define o mundo (pela nomeação). A centralidade do Humano é tão destacada que os morfemas referentes a "Humano" são mais mencionados do que aqueles referentes a todos os demais animais.

\section{Tabela 1}

Quantidade de Morfemas Referentes a "Humano" e "Animal” no Gênesis (Kawaguchi \& Guimarães, 2019)

\begin{tabular}{c|c|c|c}
\hline \multicolumn{2}{c|}{ Menções a "Humano" } & \multicolumn{2}{c}{ Menções a "animal” } \\
\hline Homem & 17 & Animais específicos & 29 \\
\hline Mulher & 18 & & \\
\hline Total & 35 & Total & 34 \\
\hline & $\mathbf{5 1 \%}$ & & $\mathbf{4 9 \%}$ \\
\hline
\end{tabular}

Já na narrativa Yanomami, existe inicialmente um mundo (não se menciona quem o criou) de caos, com animais primordiais que eram "humanos com nomes de animais" e "não paravam de se transformar" (Kopenawa \& Albert, 2015, p. 80). Aos poucos, sobretudo por ação do demiurgo Omama, os seres e coisas vão se organizando e tomando formas perenes; os animais primordiais vão se tornando os animais de caça que hoje são flechados e comidos pelos "humanos". A primeira mulher é uma mulher-peixe que é pescada por Omama, que com ela copula, dando origem aos "humanos" que se conhece hoje. Omama tinha um irmão mau, Yoasi, que, por travessura, cria a morte e as doenças - Omama se aborrece com ele, mas não tenta destruí-lo e parece aceitá-lo como parte do mundo. Antes de ir embora para outra dimensão, Omama cria os espíritos xapiri, humanos-animais que atuam como intermediários entre os viventes e os espíritos primordiais. Os xamãs, ao ingerir o pó de uma árvore chamada yãkoana, entram em contato com os espíritos xapiri, que aparecem para eles em suas imagens utupë, que são o "verdadeiro centro" de todos seres, sejam "humanos" ou animais nãohumanos, viventes ou ancestrais. Os xapiri dançam para evitar a "queda do céu”, escatologia cuja ameaça Davi Kopenawa vê materializada na invasão dos brancos, o "povo da mercadoria”, com seu garimpo e epidemias. A ancestralidade "humana", comum a todos os seres - inclusive os animais que são caçados -, é imanente, como um "passado que nunca foi presente e que, portanto, nunca passou" (Viveiros de Castro, 2006, p. 5). Assim, os animais dos quais os "humanos" hoje se alimentam são parentes dos "humanos", mas "com nomes de animais". Assim, as relações entre todos os seres, "humanos" ou não, são bilaterais e sempre referenciadas, em última instância, nos ancestrais imanentes humanos-animais utupë. A relevância cosmológica dos animais não-humanos se reflete na quantidade relativa de menções a eles na narrativa: 
Tabela 2

Morfemas Equivalentes a "Humano" e "Animal" em A Queda do Céu (Kawaguchi \& Guimarães, 2019)

\begin{tabular}{c|c|c|c}
\hline \multicolumn{2}{c|}{ Menções a "humano" } & \multicolumn{2}{c}{ Menções a "animal" } \\
\hline Humano & 29 & Animal & 38 \\
\hline Homem & 11 & Animais específicos & 166 \\
\hline Pessoa & 2 & & \\
\hline Mulher & 27 & & \\
\hline Total & 69 & Total & 204 \\
\hline & $\mathbf{2 5 \%}$ & & $\mathbf{7 5 \%}$ \\
\hline
\end{tabular}

Como se pode antecipar, a noção de "humano" na perspectiva Yanomami é completamente distinta. Na verdade, na Queda do Céu, onde na tradução se lê "humano", no original consta a palavra "Yanomami". Se nos lembrarmos do "perspectivismo ameríndio" de Viveiros de Castro (1996, 2006), notaremos que, de fato, a noção de um Humano como espécie "biológica" radicalmente distinta da "natureza" (essa sempre definida negativamente, como tudo aquilo não tocado pelo Humano) e referência absoluta e apriorística, simplesmente não existe para esta cultura: aqui, "nós" não tem a ver com "humanidade", mas com "Yanomamidade". Um animal não-humano domesticado, que vive na aldeia, é Yanomami; uma pessoa de outra etnia não o é. É por esse motivo que utilizo neste trabalho o uso de aspas na palavra "humano", quando referida no contexto Yanomami; quando referida no contexto ocidental, a palavra aparece sem aspas e com maiúscula: Humano (com exceção ao resumo deste trabalho e à primeira nota de rodapé, em que são usadas as aspas pelo motivo de que este esclarecimento ainda não havia sido feito; e aos casos em que "Humano" tem a função de adjetivo e, por isso, é grafado em minúscula); por fim, quando usada sem aspas e em minúscula, humano, a palavra aqui se refere a uma tentativa de síntese entre as perspectivas ocidental e ameríndia.

\section{Objetivos}

Realizar uma análise comparada das relações entre humanidade e animalidade em dois mitos de criação, influentes nas culturas ocidental e Yanomami. Discutir as implicações destes achados para questões epistemológicas fundamentais do pensamento psicológico.

\section{Metodologia}

A discussão é embasada num diálogo entre a antropologia do imaginário, proposta por Gilbert Durand (2012) para a análise da estrutura arquetípica $^{8}$ de expressões narrativas (como o

\footnotetext{
8 Otermo “arquétipo" foi introduzidonapsicologiaporJung(1971/1981, 1971/2000a), que os definiu como "predisposições à representação”, na mesma medida em que os instintos são "predisposições à ação", ou ainda "formas típicas de apreensão" (1971/2000b). Durand (2012) o incorporou de forma menos comprometida com as origens biológicas (embora não as negando) e mais interessada em seu funcionamento perene como "intermediário entre os esquemas subjetivos e as imagens fornecidas pelo ambiente perceptivo” (pp. 60-61)
}

mito) e a psicologia cultural (Boesch, 1991, 2000; Guimarães, 2016; Valsiner, 2012), campo dedicado à produção de sentido na tensão do encontro com o outro. Conforme mencionado na Introdução, este diálogo visa a uma complementaridade de focos na semelhança e diferença, respectivamente, de modo a se buscar uma compreensão interétnica do confronto entre os dois excertos. Para a psicologia cultural (Boesch, 1991), o "mito" é um estruturante de qualquer ato de significação, e se manifesta através de "narrativas míticas" singulares, dadas culturalmente; assim, uma narrativa hegemônica como a do Gênesis, para a cultura ocidental, está presente em qualquer construção de sentido acerca do lugar dos seres no mundo - embora sempre em diálogo construtivo com outras matrizes narrativas, ou "vozes" socioculturais (Wertsch, 1993). Desta forma, analisar o Gênesis é analisar uma estrutura ou "baliza" (Valsiner, 2012) fundamental de qualquer ato discursivo sobre a temática da ontologia dos seres na cultura ocidental. Já para Durand (2012), o "mito" é manifestação concreta de uma estrutura arquetípica anterior, que orienta sua significação. Assim, este diálogo metodológico tem como objeto duas "narrativas míticas" (Boesch, 1991), com vistas a amplificá-las em direção a uma "arquetipologia" comum (Durand, 2012), de forma que seja possível o estabelecimento de um diálogo interétnico. Por fim, o método de análise e reinterpretação por meio de antinomias aqui utilizado é aquele proposto por Guimarães (2016).

\section{Análise}

\section{Estruturas do imaginário: diurno versus noturno}

Gilbert Durand (2012) define "imaginário" como as imagens e relações entre imagens para onde convergem todas as criações do pensamento humano. Influenciado por Piaget, salienta a "incessante troca que existe ao nível do imaginário entre as pulsões subjetivas e assimiladoras e as intimações objetivas que emanam do meio cósmico e social", por meio de uma "gênese recíproca" (p. 41). Ele chama a atenção para as constelações de imagens recorrentes, "praticamente constantes" e que parecem organizadas em torno de um "isomorfismo estrutural de símbolos", variações de um mesmo arquétipo, que seria um "intermediário entre os esquemas subjetivos e as imagens fornecidas pelo ambiente perceptivo" (p. 60). Postulando primazia epistemológica às imagens arquetípicas, Durand (2012) propõe a existência de dois grandes eixos, ou "regimes", nos quais se organizam as imagens arquetípicas: diurno e noturno. Descreverei o regime noturno logo à frente. Por ora, apresento o regime diurno do imaginário, que possui a estrutura da "antítese polêmica", que é a separação irreconciliável entre opostos; da "queda à terra" e "subida aos céus", 
igualmente brusca e irrecuperável; da "pureza", ou seja, cisão extrema entre o que é e o que não é; da "luz do dia", do "céu" e do "sentido da visão", que possibilitam tais separações radicais; do "chefe", do "pai" e da "espada que corta e divide": o mundo se dá em termos de separação excludente. O Gênesis parece se encaixar neste regime do imaginário.

Considerando o ambiente árido, vasto e ofuscante em que surge o mito bíblico, temos um cenário propício à superestimulação do sentido da visão: no deserto, pode-se ver longe, pode-se ver quase tudo e a distinção entre os seres e as coisas é clara e nítida. Neste regime de saturação da visão, é razoável pressupormos uma necessidade, ao menos periódica, de se "ver menos": uma busca por alívio e descanso dos olhos, por não ver. Uma função importante do mito é prover o imaginário daquilo que lhe falta e/ou que precisa ser buscado, conectado (cf. Valsiner, 2012). No Gênesis, Deus proclama o que deve e não deve ser visto: não se deve ver o mundo com os olhos do conhecimento e, se assim o for, não se deve ver o corpo do Homem e da mulher, devendo a nudez ser coberta. Não se pode ver o que aconteceu antes do início do mundo, Adão e Eva aproveitam a ausência da visão de Deus para cometerem o pecado e assim por diante. $\mathrm{O}$ mito cria tabus por meio da restrição da visão.

O imaginário Yanomami segue um caminho distinto: Omama e Yoasi são irmãos e, apesar do primeiro ser "bom" e o segundo "mau", em nenhum momento vemos Omama tentando destruir ou tirar seu irmão mau de vista. Ele se contraria com as "travessuras" de Yoasi, mas parece considerá-lo (assim como o narrador) parte da vida, do mundo: o "mal" faz parte da criação, bem e mal são dois lados de uma só realidade. A narrativa se encaixa no que Durand (2012) chamou de regime noturno do imaginário: os "opostos se apresentam em conjunção", como partes de um só todo; são as imagens da "noite", da "lua" e do "útero": a proximidade criativa entre termos distintos e a escuridão da indefinição; do "místico", em que o outro faz parte de mim. Na narrativa Yanomami, os espíritos xapiri, apesar de "puros e perfeitos", não deixam de ter seu lado "corpóreo", "terreno" ou "impuro": defecam, fazem sexo, sentem inveja e raiva, desejam, brigam, matam, dançam e trabalham.

Não estamos no Oriente Médio, mas na floresta, com seus espaços reduzidos, por vezes escuros e com o campo de visão limitado. Aqui, os seres costumam se revelar aos ouvidos antes que aos olhos: ouve-se o canto dos pássaros, mas é difícil vê-los sobre os galhos das árvores; o rugir do jaguar (com sorte) se faz presente antes que sua imagem seja vista; o vulto dos animais que passam pode ser mais frequente que sua presença integral aos olhos; ou seja, sabe-se que o animal, ou melhor, o outro, está lá, mas não se pode vê-lo. A riqueza e diversidade da profusão de vida gerada pela floresta é propícia ao conhecimento de que nem tudo o que existe pode ser visto e, mais, a uma busca por ver, procurar descobrir quem são os seres que "estão lá". O mito parece dar conta desta função de revelação da visão.

A noção de perspectivismo ameríndio (Viveiros de Castro, 1996) nos auxilia aqui: para compreender o outro, é preciso sair de si e ocupar a perspectiva dele. Esta mudança no regime de visão é fundamental no sentido de se enxergar o outro não apesar da diferença, mas justamente $a$ partir da diferença. Assim, não só o espírito xapiri, mas qualquer outro ser no qual se pressuponha a diferença - como o animal não-humano - é um outro, um "cunhado" 9 e, partindo-se da diferença, encontra-se a semelhança: é tão "pessoa" quanto eu, mas pessoa a seu modo. "Quando um índio interage com um existente de 'outra espécie' - o que, repetimos, inclui os membros de outros coletivos que nós chamaríamos de 'humanos' -, ele sabe que está tratando com uma entidade que é humana em seu próprio departamento" (Danowski \& Viveiros de Castro, 2014, p. 96).

Contudo, vale ponderarmos que, se o conteúdo arquetípico traz consigo seu oposto em potencial, observamos que, tal qual Omama e Yoasi, na Bíblia a Serpente também não é destruída (assim como Lúcifer também não o é, posteriormente). Assim, podemos notar a possibilidade de existência do mal na narrativa bíblica, mas a forma como este surge é marcadamente diurna.

Tabela 3

Regimes do Imaginário

\begin{tabular}{c|c}
\hline Gênesis & Yanomami \\
\hline diurno & noturno \\
\hline separação excludente & opostos em conjunção \\
\hline deserto, ofuscante, visão ampla & floresta, escuridão, visão restrita \\
\hline busca por não ver & busca por ver \\
\hline
\end{tabular}

\section{No princípio o mundo ou o humano?}

O mundo bíblico é criado por Deus e, depois de pronto, está apto a ser habitado e usufruído por Adão e seus descendentes: "o Éden é um mundo-semos-humanos que é um mundo-para-os-humanos; os humanos são os últimos a chegar, e são, nesse sentido, o 'fim' (a finalidade) do mundo" (Danowski \& Viveiros de Castro, 2014, p. 37). Assim, os animais não-humanos são parte do mundo e, o Humano, dono deste mundo: observe a semelhança deste mito com a noção contemporânea de "natureza" pura e idílica, que significa "intocada pelo humano": aquilo que tem contato com o Humano já não é mais

9 Viveiros de Castro (2004) menciona o povo Kaxinawá, que usa a expressão "cunhado" para pessoas conhecidas, em situações nas quais a cultura ocidental usa "irmão": irmão é aquele com o qual temos um referencial simétrico, a "mãe” ou "pai”; já no caso do cunhado, a relação é assimétrica, pois, para um referência é a "esposa" ou "marido", mas, para o outro, é a "irmã" ou "irmão". Com isso, ele destaca a importância da diferença, e não da igualdade, para o reconhecimento das relações intersubjetivas. 
natureza, mas modificado pela "cultura”. O Humano acultura o mundo e daí a forte afiliação com o mito bíblico das noções de uma natureza radicalmente distinta de cultura.

O mito Yanomami vira do avesso a questão. O demiurgo Omama cria a terra, a floresta e a vida dos Yanomami, mas isto não quer dizer que antes não havia nada: havia a "gente yarori"10 (Kopenawa \& Albert, 2015, p. 614), ancestrais humanos com nomes de animais. Assim, as pessoas e a condição de pessoidade - que jamais se separa de animalidade - existiam desde sempre: é uma pessoa, apenas mais uma, embora especial, que cria o mundo "humano". A ordem se inverte: não é o Humano que vem tomar posse de um mundo criado para ele, como no Gênesis, mas é o "humano" que é anterior às demais coisas, ou seja, tudo tem um pouco de "humano" ou pessoa. Observe: é a natureza que é criada pela cultura (pessoas), ao contrário da ideia naturalista de cultura surgida a partir da natureza.

É importante ressaltar que o que entendemos aqui por "humanos" significa antes "antropomorfos" do que a categoria biológica ocidental (da qual penamos a nos desfazer epistemologicamente), uma vez que se trata de "pessoas" dotadas de grande variabilidade anatômica e uma moral de natureza bastante diferente dos "humanos" de hoje.

Tabela 4

Ordem das Criações (Natureza versus Cultura)

\begin{tabular}{c|c}
\hline Gênesis & Yanomami \\
\hline primeiro o mundo & primeiro as pessoas \\
\hline mundo é dado ao humano & mundo é feito por uma pessoa \\
\hline
\end{tabular}

No princípio a ordem ou o caos?

O primeiro mundo habitado no Gênesis é aquele da ordem, perfeição e pureza. No Éden, não há morte, cada ser e coisa está em seu lugar e a Humanidade convive em harmonia com Deus. Então, uma ação humana - o Pecado Original - leva Adão e Eva a habitarem o mundo de fora do Éden, o mundo do caos, condenados a uma vida próxima da terra-animalidade e longe de deus-perfeição ${ }^{11}$.

No mito Yanomami, novamente a questão se inverte: primeiro havia a gente yarori, humana com nomes de animais e que não paravam de se transformar, em um local qualquer que não era este mundo em que vivemos: o caos ontológico. Então, Omama cria a ordem: fixa cada ser no nome de um único animal, acabando com o caos, mas nem por isso apagando a ancestralidade yarori de todos os "humanos" e não-humanos. Retomarei esta questão da ordem em oposição ao caos logo a seguir.

10 Refere-se ao animal do tempo das origens, superlativo, monstruoso ou intenso. Eram ancestrais com comportamento desregrado e forma indefinida, pré-"humana”, sujeita ao devir animal. As imagens utupë desses seres primordiais são convocadas como entidades xamânicas, ou seja, xapiri.

11 Aqui em minúscula, por se referir à ideia geral de “deus”, não ao personagem judaico-cristão, este sempre grafado com maiúscula.
Vale ponderarmos que, em ambos mitos, temos a expressão da uma necessidade de ordem no caos que poderíamos compreender como relacionada ao surgimento da consciência autorreflexiva. Contudo, no Gênesis, tal ordem parece perdida em um passado que já passou ou prometida para um futuro que ainda virá; já na Queda do Céu, a ordem está aqui, no agora, da humanidade-animalidade, embora o caos yarori esteja sempre presente em imanência.

Tabela 5

Caos e Ordem

\begin{tabular}{c|c}
\hline Gênesis & Yanomami \\
\hline da ordem ao mundo de caos & do caos ao mundo em ordem \\
\hline
\end{tabular}

No princípio os humanos estavam juntos dos deuses ou dos animais?

Refletindo sobre a relação entre mito e razão, Gadamer (1954/2010) aborda a mitologia ocidental da seguinte maneira: "mitos são antes de tudo histórias sobre os deuses e suas ações junto aos homens” (p. 60). Esta asserção é verdadeira quando analisamos o Gênesis: Deus cria o mundo para o Humano, com ele interage de forma privilegiada e, no final, termina por expulsá-lo para longe, para que viva no mundo de caos e sofrimento. $O$ mito é $o$ humano junto a deus.

O imaginário ameríndio inverte a questão, conforme atesta Lévi-Strauss (Lévi-Strauss \& Eribon, 1988/1990), ao afirmar o que é um mito: "se você interrogar um índio americano, seriam muitas as chances de que a resposta fosse: uma história do tempo em que os homens e os animais ainda não eram diferentes" (p. 178). De fato, na narrativa Yanomami, os seres yarori eram "homens" e ao mesmo tempo animais, ou animais ao mesmo tempo "humanos". O mito é o humano junto aos animais não-humanos. Este quadro esquematiza esta triangulação ontológica nas duas narrativas:

\section{[VEJA FIGURA NA PRÓXIMA PÁGINA]}

No Gênesis, no início o Humano está próximo de Deus, o que implica em estar distante do mundo da animalidade. Expulso do Éden e, portanto, chegado ao tempo atual, o Humano está afastado de Deus e, assim, vivendo no lugar dos animais não-humanos, do pecado e sofrimento. O que temos é um Humano condenado a um presente em conjunção com a animalidade e, por isso, alienado de um passado irrecuperável: aquele em que era um junto a Deus, no passado mítico.

Na narrativa Yanomami, no início o "humano" também estava junto a "deus", mas isto não implica disjunção com a animalidade, pelo contrário, tratase de uma conjunção tripla: estar próximo aos "deuses" implica, necessariamente, em estar em relação direta com uma só essência, que é ao mesmo 


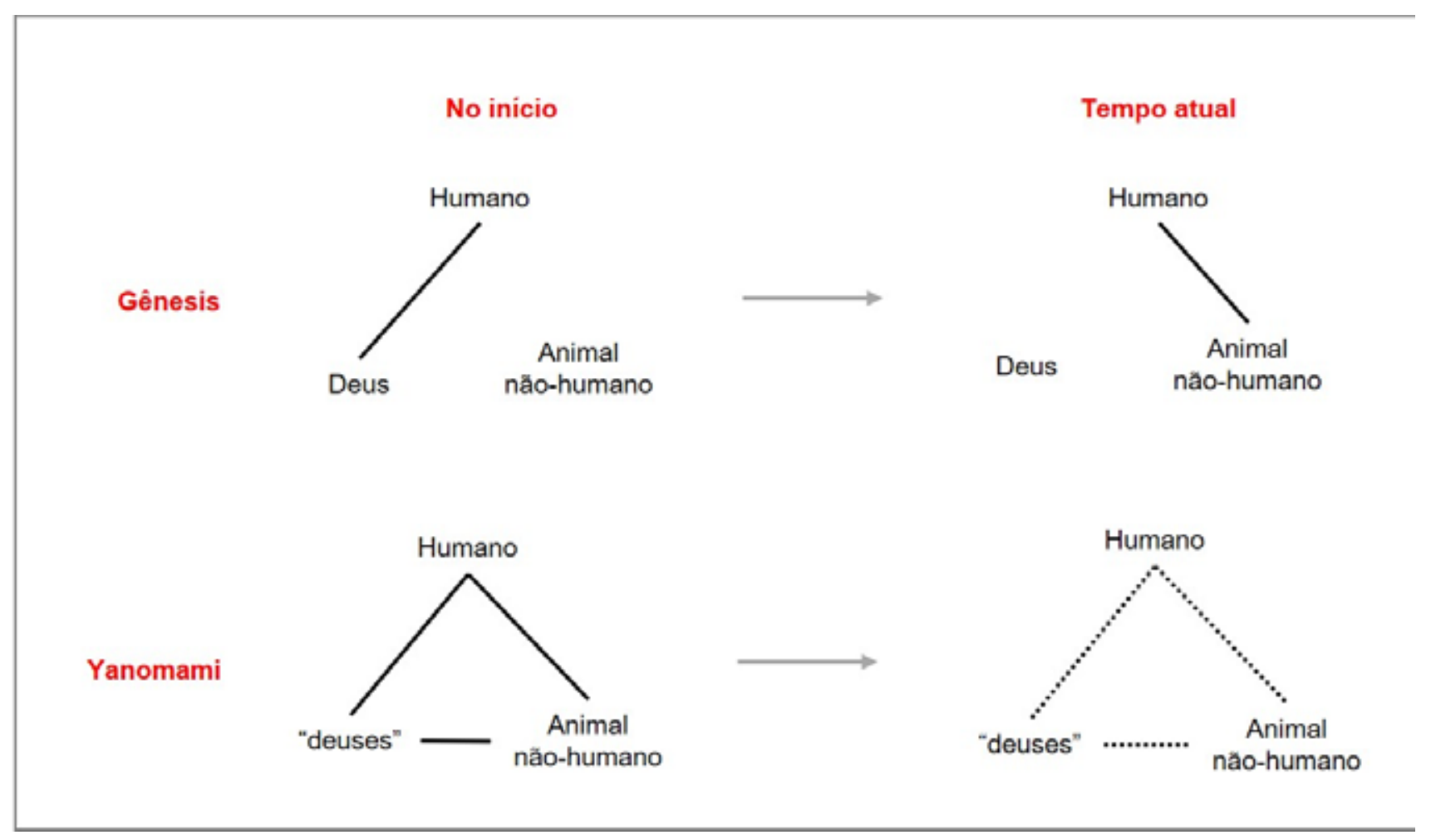

Figura 1. Humanos junto a deuses versus humanos junto aos animais.

tempo "humana" e animal. Na atualidade, o tempo mítico faz parte do passado, mas não está superado: por isso a linha tracejada, de uma relação que não faz parte totalmente do presente, mas ainda assim se manifesta por meio de uma ancestralidade imanente. Não está lá, e ao mesmo tempo está, da mesma forma como tudo o que aconteceu na vida de uma pessoa e de seus ancestrais está presente: o que somos é o resultado de tudo o que fomos e foram nossos mais longínquos ancestrais e esta herança nos influencia a cada momento de nossas vidas.

\section{O caos à espreita}

Boesch (2000) formulou a teoria do "mito do caos à espreita": o temor de que a ordem da vida e do mundo possa sucumbir ao caos a qualquer momento. Ele afirma que, em qualquer lugar ou tempo, as culturas humanas dedicaram considerável preocupação com este tema e, consequentemente, dispenderam grandes esforços para manter o caos onde ele deve ficar - à espreita -, impedindo-o de emergir na realidade. $\mathrm{O}$ autor elenca três principais formas de se controlar o caos à espreita: sacrifícios e purificações, como forma de expurgá-lo; apotropismo, que é representar o caos ou deixá-lo se manifestar de forma controlada ou encenada, ou seja, enquadrálo espacial e/ou temporalmente; e cumplicidade, motivada pela fascinação de conhecê-lo em busca da sensação de dominá-lo, ou ao menos sentir-se no controle da intenção de se deixar levar por ele.

Um exemplo do primeiro tipo são os sacrifícios astecas, de alto custo material e psicológico, em busca de se "acalmar" os deuses, evitando que o
Sol desabe sobre a terra; outros exemplos que ele cita são as cruzadas cristãs, o antissemitismo e anticomunismo, que têm em comum um desejo de se "higienizar" o caos, pressuposto como manifesto no outro, na pessoa diferente, "impura". Aos exemplos de Boesch (2000), acrescento: o racismo, a rejeição às classes mais baixas (a identificação, por "aspiração", às classes altas) e, naturalmente, no mundo ocidental, a rejeição e purificação do que possa haver de animalidade dentro de nós noção que explorarei logo adiante. A segunda forma de se controlar o caos à espreita, segundo o autor, é exemplificada pela literatura, artes dramáticas ou o carnaval: delimita-se um espaço onde o caos possa se manifestar livremente, de modo a termos a tranquilidade de saber que podemos encerrálo fechando o livro, ao final da peça ou na Quarta de Cinzas. E a terceira forma é exemplificada nos horrores do nazismo e da Revolução Francesa: para repelir a ameaça do terror vinda do outro, eu me transformo no próprio terror.

Para Boesch (2000), a batalha contra o caos é frequentemente imaginária e a ameaça internalizada em cada um de nós, na forma de culpa. Por isso, ele menciona a religiosidade como uma forma importante de canalização do mito do caos à espreita, sobretudo na forma de purificação: para ele, o mito precede a religião. Outras duas formas de se canalizar o caos potencial interno, para ele, são a moralidade e a arte. Ora, religiosidade, moralidade e arte são componentes essenciais do mito, tal qual ele é manifesto nas culturas tradicionais. 
Se a ameaça do caos é temida, então o que é desejado? Qual seu oposto? Para Boesch (2000), seria a "ordem do paraíso", uma ideia, para ele, de estruturação profunda e universal, tão mítica quanto a ameaça do caos. Esta oposição entre caos e ordem traz um interessante eixo de comparação entre o imaginário bíblico e o Yanomami: como apontei há pouco, o Gênesis professa um pré-mundo onde tudo é ordem e um mundo pós-mítico onde tudo é caos, sofrimento e onde o Humano é condenado por um pecado que já está, inevitavelmente, dentro de si; na Queda do Céu, o pré-mundo é caos, até que Omama vem pôr ordem nas coisas e, então, o mundo pósmítico é ordem.

Na Bíblia, a Serpente não força Eva a cometer o pecado, apenas a persuade: no final das contas, $a$ escolha é dela. Observe que o pecado não é "trazido" pela Serpente, ao contrário: já estava dentro de Eva, ou seja, do Humano. Assim, na Bíblia, o pecado é o caos interno sempre ameaçando se realizar, mediante a tentação, ou seja, uma persuasão externa: o caos está dentro e pode ser realizado por influência da animalidade que está fora, ameaçando a ordem.

Se tomarmos ambos, a Serpente como animalidade portadora da ameaça do caos e condenada à vida rastejante, e o Humano, condenado a uma vida próxima dos animais não-humanos e longe de Deus, sendo que esta vida no mundo do pecado é a vida do caos, temos um mito da animalidade como caos a ser purificado, extirpado, extinto mediante sacrifício e o controle das paixões e do que compartilhamos com os demais animais: o corpo.

Na narrativa Yanomami, o caos a ser repelido é a ameaça da queda do céu e é a partir desta profecia de iminente destruição do mundo que podemos entender toda a ritualização envolvida no trato deste povo para com o ambiente e os seres não-humanos - ou seja, para com a natureza, numa denominação naturalista. Aos olhos ocidentais, os penosos rituais de purificação realizados pelos povos ameríndios após a caçada de um animal podem parecer apenas um "exotismo" irracional, mas tomando conhecimento da perspectiva Yanomami, o que vemos parece ser uma profunda sabedoria a respeito da importância do cuidado para com o equilíbrio de um sistema que, há muito sabem, é fundamentalmente delicado: o equilíbrio do mundo. A epidemia xawara, trazida pelo mesmo "povo da mercadoria" que traz os tratores e as ferramentas do garimpo para destruir a floresta é mais do que a ameaça do caos: é o caos em si mesmo, vivo e concreto. Conforme observamos ao longo de toda a narrativa de Kopenawa, os espíritos xapiri exercem a função fundamental de dançar para que o céu continue em seu lugar e a epidemia xawara não dizime o povo Yanomami - e daí o ritual xamânico de purificação, com a "morte" por meio do consumo do pó yãkoana.

O caos, para o Yanomami, não está na animalidade, ao contrário: é repelido pelo contato com ela, intermediado pelos xapiri. Na Bíblia, o lugar a ser buscado é o da pureza, da proximidade com Deus, da ordem e do distanciamento do animal não-humano, enquanto o lugar a ser evitado é o do pecado, do animal que rasteja e do corpo. Assim, é de se esperar que o espírito esteja conectado com o céu e que a pureza seja resgatável somente após a morte, ou seja, após o abandono da corporeidade e, portanto, da animalidade - neste sentido, é transcendente. Daí, não é difícil compreendermos os paradigmas de privação do corpo e da vida na terra.

Para os Yanomami, ao contrário, o espírito está no corpo, é imanente e manifesto a partir da relação com o mundo, com os animais não-humanos e todos os demais seres, ou seja, está na terra. A animalidade está em todos nós, tanto pelo corpo, em si, quanto pela ancestralidade distante dos yarori e, ainda mais relevante, na ancestralidade próxima de $T^{h} u e ̈ y o m a$, a mulher-peixe, esposa de Omama e da qual toda a "humanidade" descende. É interessante a distinção que Kopenawa faz quanto ao "peito" e as "costas" do céu (Kopenawa \& Albert, 2015, p. 111): o peito, parte da frente, é onde estão o Sol, as estrelas, enfim, tudo o que se vê; as costas, ao contrário, são o lado que não vemos ordinariamente, mas nem por isso duvidamos de que esteja lá: é onde estão os mortos e os seres monstruosos, ancestrais. Notemos que os espíritos xapiri são os intermediários entre os seres da floresta, os do peito e os das costas do céu: conectam os três mundos, ou seja, os espíritos não estão apenas "no céu", mas tem relação essencial com a terra e a corporeidade.

Mas isso não quer dizer que não exista, na cosmologia Yanomami, uma ideia como a de busca pela pureza.Porumlado, apesar desuascaracterísticas especiais, que os destacam da vida ordinária dos vivos, os xapiri não deixam de ter os hábitos, modos de vida, qualidades e defeitos daqueles de quem são imagens, ou seja, são da terra e parecem-se muito mais com os vivos do que as entidades divinas cristãs. Por outro lado, são mais limpos e puros: não se deslocam pela terra, por achá-la "suja demais, coberta de detritos e excrementos" (Kopenawa \& Albert, 2015, p. 126) e, mais importante, não comem carne de caça nem bebem a água dos rios, que é suja (Kopenawa \& Albert, 2015, p. 128). Assim, temos, de um lado, um distanciamento quanto ao mito bíblico, por conta de os espíritos fazerem as mesmas coisas que os vivos; de outro, uma aproximação, por conta de o fazerem de forma "perfumada", ou seja, com pureza, limpeza e beleza superior às entidades "terrenas". Mais ainda, se pensarmos em Jesus Cristo como a corporificação de Deus, então temos também, na narrativa bíblica, a sinalização para uma proximidade das relações entre espírito e corpo. Assim, temos, sim, na narrativa Yanomami, a noção de pureza e limpeza relacionada aos espíritos, mas essa não se dá enquanto expurgação da animalidade não-humana; e temos, na narrativa 
bíblica, a animalidade divina, porém, esta ainda se dá em oposição quanto à animalidade não-humana.

Há ainda uma outra importante aproximação entre ambas narrativas: a alimentação carnívora está, em ambas, envolta em restrições e tabus. Assim como na Bíblia a morte por predação parece um tema evitado, na Queda do Céu a "crueldade" está associada a certos xapiri que se alimentam da carne humana. Lembrando do "perspectivismo ameríndio" de Viveiros de Castro (1996), observamos que, se os Yanomami julgam os espíritos da onça, do gavião e do urubu cruéis por caçarem "humanos", hão de pressupor que os espíritos dos queixadas também nutram o mesmo sentimento quanto aos "humanos". Ou seja, não há crueldade em si no ato de se matar o outro para comê-lo, o que há é uma percepção perspectivista, relativa, da crueldade: mau é aquele que quer me caçar. A maldade é relativa à posição que se ocupa.

O que estou sugerindo é que, embora existam aproximações entre ideias gerais nas cosmologias bíblica e Yanomami - como a tensa elaboração psicológica quanto às relações de predação e a busca pela pureza e ordem -, a forma como se lidar com elas é, no mais das vezes, oposta entre ambas. $\mathrm{Na}$ Bíblia, a causa do mal é apontada fora: a serpente, animalidade que evito, para evitar que suscite a animalidade em mim, é depositada no outro: estamos no "regime diurno" do imaginário (Durand, 2012), de separação e corte; na Queda do Céu, ao contrário, estamos no "regime noturno", de união e conjunção entre opostos: o outro é integrado a mim, o mal faz parte de minha interioridade e o controle do caos se faz por meio da integração, não da repulsa. De um lado, separação exclusiva; do outro, dialogicidade inclusiva.

Boesch (2000) defende a universalidade do "mito de que o destino do mundo depende do resultado da batalha entre... bem e mal, luz e escuridão" (p. 5). Fica a questão: será que a palavra "batalha" seria a mais abrangente culturalmente? Talvez "batalha" seria uma forma mais ocidental de se lidar com o caos à espreita. Será que para os Yanomami não seria mais adequado dizermos "devoro", por exemplo? O apontamento de onde está o mal pode dizer bastante sobre a forma como lidar com a animalidade nestas duas narrativas míticas.

\section{Presa e predador, dono ou cuidador}

O termo "caça" aparece 27 vezes em 30 páginas da narrativa de Kopenawa, o que dá uma dimensão da relevância do animal não-humano que se tornará alimento do "humano". Mais do que apenas "carne", o animal não-humano é "caça", é "presa": é um sujeito. Mais do que um tecido sem vida, história, parentesco ou subjetividade a ser ingerido (a carne), temos o animal em sua integridade, com seu papel enquanto sujeito: aquele que se comporta como caça e que, dedutivamente, em um dado momento esteve vivo e oferecendo uma polaridade inversa em relação ao predador. Isto tem estreita relação com as proposições de Carlos Fausto (2008) quanto à noção de cuidado nos povos indígenas amazônicos: dono é aquele que cuida, de modo que temos a figura da pessoa que cuida da casa, dos objetos ritualísticos, mas também daquele espírito que cuida dos queixadas da floresta, para o qual deve-se pedir licença para caçar. Da mesma forma, o animal doméstico está aos cuidados do humano ameríndio e tradicionalmente não é executado para alimentação. A noção de cuidado pressupõe um sujeito cuidador e outro sujeito que é cuidado - diferente da relação entre sujeito e objeto pressuposta na criação de mundo bíblica.

É interessante a noção de Kopenawa de que os seres "maléficos" são aqueles que, mesmo sendo espíritos, caçam e se alimentam do "humano" (Kopenawa \& Albert, 2015, p. 124). A condição dos seres enquanto simultaneamente predador e presa, em vez de silenciada, como parece ser preponderante na narrativa bíblica, se faz presente em todas as dimensões, de forma perspectivista. Para o Yanomami, maléfico é aquele que se alimenta de mim, ou seja, a definição de "mal" depende de minha perspectiva; mas, num mundo onde o humano não pode mais ser presa, como é no caso da "civilização", esta perspectiva deixa de fazer sentido. Se entendermos a Bíblia como uma narrativa estruturante do imaginário eurocêntrico (pouco importa se na origem ou na adoção histórica), podemos apontar sua influência para a noção, presente em diversas narrativas ocidentais, de que o ato da predação, em si, é um ato maléfico. Observe as consolidadas narrativas de Tom e Jerry, PapaLéguas e Os Três Porquinhos: quem é algoz e quem é a vítima? Do lado do mal, temos o predador, que é mau porque quer se alimentar do outro; do lado do bem, aquele que procura não se tornar presa, mas que, curiosamente, não é predador de ninguém: não se alimenta?

Uma última distinção importante entre as duas narrativas é quanto ao fazer: o Deus bíblico cria o mundo em seis dias e, após isso, estabelece restrições, punições e dá ordens, ou seja, manda fazer e não fazer. O mandar fazer traz consigo uma relação de subjugação, em que o subjugado tem sua subjetividade reduzida (pouco podemos quanto ao poder de Deus), é dominado: este paradigma de dominação parece transferido para as relações entre Humano e animal não-humano, que é sua propriedade. De forma diferente, Omama reorganiza o mundo, muito mais do que o cria: a criação já estava feita, as coisas estavam aí, os humanos-animais se transformando sem parar, o caos acontecendo. Omama então vai lá e muda o estatuto dos seres e coisas, pesca sua mulher-peixe, copula com ela e assim nascem os "humanos". Omama não dá ordens nem prescrições, ele faz os seres e a partir daí cada 
um toma seu caminho. A diferença entre o mandar e o fazer é a diferença entre uma relação sujeitoobjeto e uma sujeito-sujeito: fazer é transformar, é dar um pouco de si para o que se faz, envolver-se, trocar. Plantar uma árvore é fazer dela meio sua, meio da terra: ela não estaria lá sem sua ação, mas também não sem a terra. O fazer favorece as relações intersubjetivas; o mandar, as unidirecionais.

\section{Considerações Finais}

"E é por isso que vale a pena estudar outros povos, porque toda compreensão de uma outra cultura é um experimento com nossa própria cultura” Roy Wagner (1981/2010, p. 41)

A partir da psicologia cultural, pudemos observar uma mesma palavra - humano, "nós" ou "animal" - significando noções totalmente distintas para diferentes culturas, ou seja, tivemos um olhar com destaque para a diferença. Aprofundamos a compreensão da forma como isso ocorre especificamente no encontro interétnico extremo entre dois mitos de criação que influenciam a cosmovisão de duas culturas. Mas a diferença é apenas um polo da compreensão do outro. A partir da antropologia do imaginário, observamos a coincidência significativa, a semelhança que antecede a própria palavra, através do arquétipo. Se as palavras são criadas arbitrariamente num contexto cultural específico, e nesse sentido são únicas, por outro lado remetem a uma necessidade de significação que está presente muito antes do surgimento delas: a distinção entre bom e mau, e entre nós e eles, precede em muito a linguagem. Assim, encontramos, naturalmente, tanto na cultura Yanomami quanto na ocidental, influenciada pelo mito bíblico, as ideias fundamentais de nós e ele, bom e mau, junto e separado, criação e fim e ordem e caos, mas, diferentemente do que se poderia esperar a partir das matrizes hegemônicas de pensamento psicológico, não encontramos na narrativa Yanomami a ideia de humanidade, contrastada com animalidade, o que dá uma ideia da arbitrariedade e especificidade de tal noção. A humanidade é, assim, antes uma invenção que um dado apriorístico.

Se entendemos os regimes diurno e noturno do imaginário como também fundamentais, ou seja, arquetípicos, como defende Durand (2012), então temos a hipótese de uma estruturação que pode ter influência sobre esta noção de que a humanidade enquanto identidade seria dada, natural, para todos os Humanos. Em outras palavras, será que esta visão, que se pensa antropocêntrica, mas que, pelo que aqui vimos, seria antes etnocêntrica, não seria ela mesma apoiada sobre uma base arquetípica de cisão radical (no caso, entre Humano e natureza)? Se sim, será que a categoria de separação continuaria a ser necessariamente esta, a humanidade, caso os rumos históricos da modernidade fossem outros (se, por exemplo, as fronteiras que se dissolveram no fim da Idade Média estivessem de pé até hoje, impedindo o intenso intercâmbio cultural em que surgiu a ideia do humano como referência cosmológica)? Este é um outro problema que, por si só, demandaria um outro trabalho, mas, para nossos propósitos aqui, caberia nos questionarmos se a enorme influência da cosmologia bíblica sobre a visão ocidental do lugar do humano e dos animais não-humanos no mundo não corresponderia a uma unilateralidade do regime diurno do imaginário.

Se assim for, temos pela frente, enquanto cultura, um trabalho imenso de reconciliação dialógica com o aspecto noturno do imaginário referente às relações entre humanidade e animalidade, em direção a uma condição mais íntegra e condizente com a complexidade e profundidade de quem somos. Talvez, se nos preocupássemos menos com o que haveria de tão especial na condição humana, e nos questionássemos mais tendo como base as inúmeras outras categorias ontológicas com as quais podemos nos identificar, encontraríamos respostas mais satisfatórias para algumas perguntas fundamentais do pensamento psicológico. Observe que não estamos falando aqui do resgate de um vitalismo harmonioso, de uma natureza idílica, romântica e inocente, supostamente perdida em algum lugar do passado. Ao contrário, estamos em busca de uma animalidade que ainda está para ser inventada, uma vez que deverá, necessariamente, ser construída sobre todo o enorme edifício do antropocentrismo que nos trouxe até a criação da psicologia, e dela até os dias de hoje. Uma desconstrução e reconstrução de nossa integralidade humano-animal, portanto - não o resgate de uma natureza desprovida de subjetividade.

Temos motivos para supor que o diálogo criativo entre semelhança e diferença também seja fundamentalmente arquetípico. Se assim for, este diálogo entre psicologia cultural e antropologia do imaginário pode representar um avanço para o pensamento psicológico, no sentido de conciliar a singularidade com a coletividade da qual todos somos parte. É preciso reconhecer a enorme igualdade que existe entre mim e um animal nãohumano, para que então eu possa empatizar com suas diferenças e singularidades - que, vale lembrar, estão presentes não apenas num animal, mas em qualquer ser, humano ou não, diferente de mim. É possível que, a partir desta tensão entre semelhança e diferença, tomemos consciência do quão pouco somos, ou precisamos ser, humanos - e que este vislumbre tire de nossos ombros muito do peso de uma cosmogonia secular sobre como deveríamos ou poderíamos ser, sentir, pensar, agir, desejar, temer, nos comportar e existir. Esta virada de perspectiva pode ser contributiva para o pensamento psicológico em seu sentido amplo. 


\section{Referências}

Bíblia de Jerusalém. (2002). São Paulo, SP: Paulus.

Boesch, E. E. (1991). Symbolic action theory and cultural psychology. Berlin-Heidelberg-New York: Springer.

Boesch, E. E. (2000). The myth of lurking chaos. In Keller, H., Poortinga, Y., \& Schölmerich, A. (Eds.). Between biology and culture: Perspectives on ontogenetic development. Cambridge: England: Cambridge University Press.

Chapman, J. V. (2015). 10 most read books in the world. HubPages. Recuperado de http://hubpages.com/literature/mostreadbooks

Danowski, D., \& Viveiros De Castro, E. (2014). Há mundo por vir? Ensaio sobre os medos e os fins. Desterro (Florianópolis), SC: Cultura e Barbárie: Instituto Socioambiental.

Descola, P. (1996). Constructing natures: Symbolic ecology and social practice. In Descola, P., \& Palsson, G. (Orgs.) Nature and society: anthropological perspectives (pp. 82102). New York, NY and London: England: Routledge.

Descola, P. (2005). Par-delà nature et culture. Paris: Gallimard.

Durand, G. (2012). As estruturas antropológicas do imaginário: Introdução à arquetipologia geral. São Paulo, SP: WMF Martins Fontes.

Fausto, C. (2008). Donos demais: Maestria e domínio na Amazônia. Mana, 14(2), 329-366.

Gadamer, H-G. (2010). Hermenêutica da obra de arte. São Paulo, SP: Martins Fontes (Original de 1954).

Guimaraes, D. S. (2016). Descending and ascending trajectories of dialogicalanalysis: seventh analytic interpretation on the short story "The guerrillero". Psicologia USP, 27(2), 189-200. doi: http://dx.doi.org/10.1590/0103$\underline{6564 \mathrm{D} 20160003}$

Guinness World Records. (2016, julho). Best selling book of non-fiction. Recuperado de http://www.guinnessworldrecords.com/world-records/best-selling-book-of-non-fiction

Hammack, P. L. (2010). The cultural psychology of Palestinian youth: A narrative approach. Culture \& Psychology 16(4), 507-537. doi: 10.1177/1354067X10380159

Jung, C. G. (1981). Estudos sobre psicologia analítica. Petrópolis, RJ: Vozes (Original publicado em 1971).

Jung, C. G. (2000a). Os arquétipos e o inconsciente coletivo. Petrópolis, RJ: Vozes (Original publicado em 1971).

Jung, C. G. (2000b). A natureza da psique. Petrópolis, RJ: Vozes (Original publicado em 1971).

Kawaguchi, D. (2017). Todo mundo é humano? A relação entre humanidade e animalidade nas narrativas míticas de duas culturas. Dissertação de mestrado, Instituto de Psicologia, Universidade de São Paulo, São Paulo, SP.
Kawaguchi, D. \& Guimarães, D. S. (2019). Is everybody human? The relationship between humanity and animality in Western and Amerindian myth narratives. Culture \& Psychology, 25(3), 375-396. doi: 10.1177/1354067X18779058

Kopenawa, D., \& Albert, B. (2015). A queda do céu: Palavras de um xamã yanomami. São Paulo, SP: Companhia das Letras.

Lévi-Strauss, C., \& Eribon, D. (1990). De perto e de longe: Reflexões do mais importante antropólogo de nosso século. Rio de Janeiro, RJ: Nova Fronteira. (Original publicado em 1988).

Simão, L. M. (2010). Ensaios dialógicos: compartilhamento e diferença nas relações eu-outro. São Paulo, SP: Hucitec.

Valsiner, J. (2012). Fundamentos da Psicologia Cultural: mundos da mente, mundos da vida. São Paulo, SP: Artmed.

Viveiros de Castro, E. (1996). Os pronomes cosmológicos e o perspectivismo ameríndio. Mana, 2(2), 115-144.

Viveiros de Castro, E. (2004). Perspectival Anthropology and the method of controlled equivocation. Tipití: Journal of the Society for the Anthropology of Lowland South America, 2(1), 3-22.

Viveiros de Castro, E. (2006). A floresta de cristal: nota sobre a ontologia dos espíritos amazônicos. Cadernos de Campo, 14/15, 319-338.

Viveiros de Castro, E. (2015). O recado da mata [Prefácio]. In Kopenawa, D., \& Albert, B. A queda do céu: palavras de um xamã yanomami (B. Perrone-Moisés, trad., pp. 1141). São Paulo, SP: Companhia das Letras.

Wagner, R. (2010). A invenção da cultura (M. C. Souza, \& A. Morales, trads.). São Paulo, SP: Cosac Naify. (Original publicado em 1981)

Wertsch, J. V. (1993). Voices of the mind: A sociocultural approach to mediated action. Cambridge: England: First Harvard University Press.

Douglas Kawaguchi (https://orcid.org/0000-00031608-5857), Instituto de Psicologia da Universidade de São Paulo - InterPsi - Laboratório de Estudos Psicossociais: crença, subjetividade, cultura \& saúde. Email: douglaskawaguchi@gmail.com

Recebido em 30.07.2019

Primeira Decisão Editorial em 17.02.2020 Segunda Decisão Editorial em 26.08.2020

Aceito em 16.06.2021 